\title{
Inflammatory bowel disease-like enteritis and caecitis in a senescence accelerated mouse P1/Yit strain
}

S Matsumoto, Y Okabe, H Setoyama, K Takayama, J Ohtsuka, H Funahashi, A Imaoka, Y Okada, Y Umesaki

\begin{abstract}
Background-A new subline of the senescence accelerated mouse (SAM) P1/Yit strain has been established which shows spontaneous enteric inflammation under specific pathogen free (SPF) conditions. Aims-To elucidate the pathogenesis of enteric inflammation in this new subline. Methods-The SPF and germ free (GF) SAMP1/Yit strains were used. Histological, immunological, and microbiological characterisation of the mice with enteric inflammation was performed.

Results-Histologically, enteritic inflammation developed as a discontinuous lesion in the terminal ileum and caecum with the infiltration of many inflammatory cells after 10 weeks of age. The activity of myeloperoxidase, and both immunolocalisation and mRNA expression of inducible nitric oxide synthase increased in the lesion. CD3- $\varepsilon$ positive $T$ cells, neutrophils, and macrophages were more numerous in the inflamed mucosa of the SAMP1/Yit strain. The GF SAMP1/Yit strain did not show any inflammation in the intestinal wall, by the age of 30 weeks, and the enteritis and caecitis developed 10 weeks after the conventionalisation of the GF SAMP1/Yit strain.

Conclusion-Enteric inflammation in the ileum and caecum developed in the SAMP1/Yit strain. The pathophysiological characteristics of the disease in this mouse have some similarities to those of human inflammatory bowel disease (IBD). This mouse strain should be a useful model system for elucidating the interaction between the pathogenesis of IBD and the gut microflora.

(Gut 1998;43:71-78)
\end{abstract}

Keywords: inflammatory bowel disease; enteritis; caecitis; senescence accelerated mouse

Inflammatory bowel disease (IBD) is a noninfectious, chronic intestinal inflammation which is comprised of ulcerative colitis and Crohn's disease. IBD is a complex intestinal disorder and its pathogenesis is not well understood. A recent study indicated that mice with gene targeted disruption of interleukin 2 (IL-2), IL-10, class II MHC, or T cell receptor $\alpha$ or $\beta$ developed chronic intestinal inflammatory disease. ${ }^{1-3}$ Powrie et al showed that after injection of CD45RB high $\mathrm{CD} 4 \mathrm{~T}$ cells, scid mutant mice developed the same disease, and that the disease could be prevented by coinjection of the CD45RB ${ }^{\text {low }} \mathrm{CD} 4 \mathrm{~T}$ cell subset. ${ }^{4}$ Immunosuppressive agents, such as cyclosporin $\mathrm{A}$, have a beneficial effect on human IBD. ${ }^{5}$ These results suggest that the collapse of gut immune homoeostasis is the major cause of the chronic intestinal inflammatory disease in animal models and human IBD patients. One hypothesis for the pathogenesis of IBD is that the disease is due to an abnormal response of the gut immune system to normal gut luminal contents such as the intestinal microflora or food antigens. To determine which gut luminal contents are responsible for the progression of chronic intestinal inflammation, it is desirable to establish animal models which naturally develop IBD-like intestinal inflammation. However, a spontaneously occurring IBD-like model is rare in mice. ${ }^{6}$ Experiments have therefore been conducted with drug induced models, such as the dextran sodium sulphate and hapten induced models. ${ }^{7-9}$ Drug induced models are not suitable for studies on the pathogenesis of IBD, owing to complex interactions between genetic and environmental factors, because the enteric inflammation occurs through non-specific mechanisms.

Senescence accelerated mice (SAM) were derived from AKR/J mice established by Takeda et al. ${ }^{10}$ The SAMP1 strain is one of the series of senescence prone strains established by breeding 24 generations of siblings from a litter of $\mathrm{AKR} / \mathrm{J}$ mice derived from the Jackson Laboratory (Bar Harbor, Maine, USA). SAMP1 mice have a short life span (approximately nine months) and show early signs of senescence such as spontaneous amyloidosis, alopecia, and osteoporosis. ${ }^{11-13}$ It has been reported that SAMP1 mice show impaired immune functions with age, such as in the $\mathrm{T}$ dependent antibody response due to a decrease in helper T cell function. ${ }^{14}{ }^{15}$ Our subline of the SAMP1 strain, named the SAMP1/Yit strain, showed enteric inflammation. In this study, we studied the pathological features of gut inflammation of the SAMP1/Yit strain and the effect of gut microflora on pathogenesis of the enteric inflammatory disease.

\section{Materials and methods}

ANIMALS

The SAMP1 strain was kindly provided by Dr T Takeda, Kyoto University, Kyoto, Japan. For the establishment of the new subline, SAMP1 strain mice showing spontaneous skin ulceration were
Tokyo 186-8650, Japan.

Accepted for publication 19 January 1998 

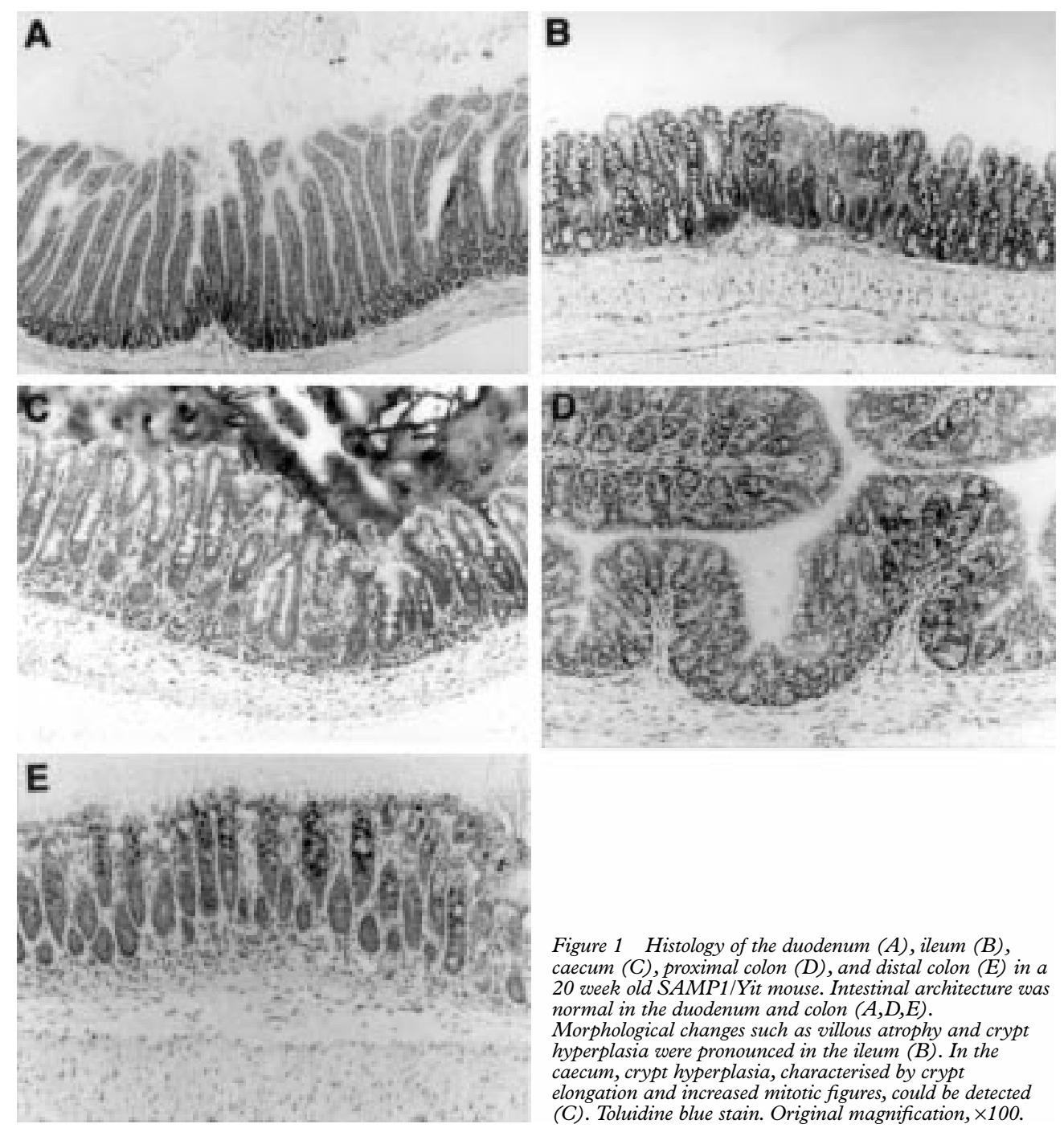

Figure 1 Histology of the duodenum (A), ileum (B), caecum (C), proximal colon (D), and distal colon (E) in a 20 week old $S A M P 1 / Y i t$ mouse. Intestinal architecture was normal in the duodenum and colon $(A, D, E)$.

Morphological changes such as villous atrophy and crypt hyperplasia were pronounced in the ileum $(B)$. In the caecum, crypt hyperplasia, characterised by crypt elongation and increased mitotic figures, could be detected (C). Toluidine blue stain. Original magnification, $\times 100$.

selected and mated. Mice showing skin lesions were selected in the F1 generation of this strain and brother-sister mating performed over 20 times so as to establish the SAMP1/Yit strain. This strain showed no amyloidosis and no shortened life span, unlike the original SAMP $1 .{ }^{11}$ In addition, inflammatory disease in the ileum was observed in this new subline. Inflammation of the gut in this new subline was associated with the presence of the skin lesions. No differences were detected in the standard genetic markers between the Yit strain and the original strain in the chromosomes tested: Chr 1 (Idh 1, Pep 3, Akp 1, Apo a2), Chr 2 (Hc), Chr 3 (Car 2), Chr 4 (Mup 1, Gpd 1), Chr 5 (Pgm 1), Chr 6 (Ldr 1), Chr 7 (Gpi 1, Hbb), Chr 8 (Es 1, Es 2), Chr 9 (Thy 1, Trf), Chr 11 (Es 3), and Chr 17 (H 2K, H 2D).

The mice were maintained under specific pathogen free (SPF) conditions using the barrier system and fed a sterilised pelleted diet and water. The germ free (GF) SAMP1/Yit strain was generated in our institute and kept in sterilised vinyl isolators. The GF condition was checked monthly according to requirements of the Japan Experimental Animal Research Association. ${ }^{16}$ Control AKR/J mice were pur-

chased from Seiwa Experimental Animals Ltd (Fukuoka, Japan).

PATHOGEN ANALYSIS

Serological tests were negative for Helicobactor hepaticus, Corynebacterium kutscheri, Mycoplasma pulmonis, ectromelia virus, mouse adenovirus, mouse hepatitis virus, Sendai virus, and Salmonella typhimurium. Faecal cultures were negative for Escherichia coli 0115, Pseudomonas aeruginosa, and Salmonella spp. Lung cultures were negative for Pasteurella pneumotropica. Direct smears of the colonic contents were negative for Giardia muris, Spironucleus muris, and Syphacia spp.

HISTOLOGICAL EXAMINATION

Tissue sections $(5 \mu \mathrm{m})$ of the duodenum, jejunum, ileum, caecum, colon (proximal and distal colon), and rectum of 5-30 week old SAMP1/Yit strain mice were prepared with a cryotome in the standard manner. In addition, sections from skin, salivary glands, lung, pancreas, stomach, liver, and kidney of 20-30 week old SAMP1/Yit mice were made in the same manner. The sections were stained with toluidine blue. For immunohistochemical 


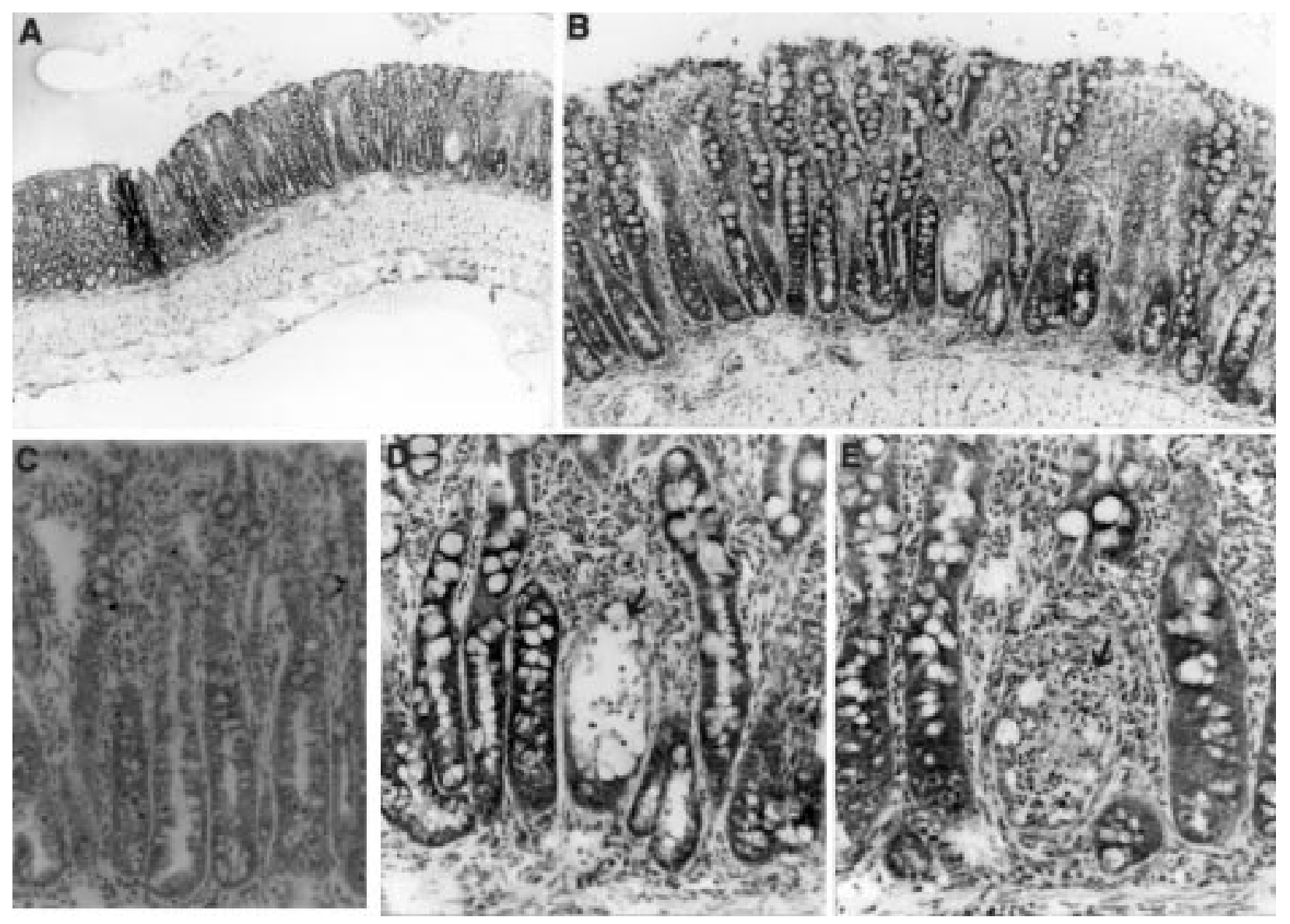

Figure 2 Histological analysis of the ileum of a SAMP1/Yit mouse at 20 weeks of age. (A) Low magnification photograph of inflammatory bowel disease in the ileum of a 20 week old SAMP1/Yit mouse. The intestinal walls were thickened due to the inflammation. (B) High power view of $A$ showing severe mucosal inflammation. Crypt hyperplasia with crypt elongation, and villous atrophy were pronounced in the lesion. Inflammatory infiltrate could be observed in the LP and submucosa. (C) Enlargement of the lymphatic vessels could be seen in the LP. (D) Higher magnification of B showing crypt undergoing necrosis (arrow) with intraluminal neutrophils. Mixed inflammatory cell infiltrate in the LP predominantly consisted of macrophages, neutrophils, and lymphocytes. (E) Crypt loss (arrow) is associated with necrotic debris in crypts. Toluidine blue stain, original magnification: A, $\times 40$; $B, \times 100 ; C, \times 200 ; D, E \times 400$.

analysis, the sections were fixed with ice cold acetone $\left(-20^{\circ} \mathrm{C}\right)$ and then incubated with the optimal dilution of monoclonal antibodies ER-TR-23 (BMA Biomedicals, Rheinstrasse, Switzerland), Gr-1 (Pharmingen, San Diego, California, USA), or 500-A2 (Pharmingen) which react with tissue macrophages, granulocytes, and CD $3-\varepsilon$, respectively. For the detection of inducible nitric oxide synthase (iNOS), polyclonal rabbit IgG against mouse iNOS (UBI, Lake Placid, New York, USA) was used. Finally, the tissue sections were stained with a 3',3-diaminobenzidine solution. Endogenous peroxidase was blocked with $1 \%$ sodium periodate.

ONTOGENIC STUDY

To investigate the effect of aging on the development of intestinal lesions in SAMP1/Yit strain mice, we examined the presence of enteric inflammation in the SPF SAMP1/Yit strain from age 5 to 30 weeks. A $10 \mathrm{~cm}$ length of the proximal part of the small intestine and ileum was excised from $5,10,15,20,25$, and 30 week old SAMP1/Yit mice $(n=6)$, or from 15,20 , and 25 week old control AKR/J mice $(n=6)$. The intestinal contents were flushed out with ice cold $10 \mathrm{mM}$ PBS ( $\mathrm{pH} 7.2$ ) with a syringe and then the remaining PBS was removed with filter paper (Toyo Roshi Kaisha Ltd, Japan). The intestinal segments were weighed and histological examination performed.

REVERSE TRANSCRIPTION-POLYMERASE CHAIN REACTION ANALYSIS

Total RNA was extracted from the ileal segments from 5-30 week old SPF SAMP1/Yit strain mice with TRI-sol (Gibco BRL, Gaithersburg, Maryland, USA). Glyceraldehyde 3-phosphate dehydrogenase (G3PDH) and iNOS mRNA were detected by reverse transcription-polymerase chain reaction (RTPCR). Specific primers for murine G3PDH and iNOS were purchased from Clonetech Laboratories Inc. (Palo Alto, California, USA). Reverse transcription was performed at $42^{\circ} \mathrm{C}$ for 30 minutes. cDNA was amplified for 32 cycles. The PCR conditions were denaturation at $72^{\circ} \mathrm{C}$ for one minute, annealing at $60^{\circ} \mathrm{C}$ for 45 seconds, and extension at $40^{\circ} \mathrm{C}$ for $45 \mathrm{sec}-$ onds. The PCR products were then analysed by electrophoresis in a $1.5 \%$ agarose gel.

MEASUREMENT OF TISSUE MYELOPEROXIDASE Tissue myeloperoxidase (MPO) activity was measured as described by Krawisz et al. ${ }^{17}$ In brief, ileal tissue from 20 week old SAMP1/Yit 


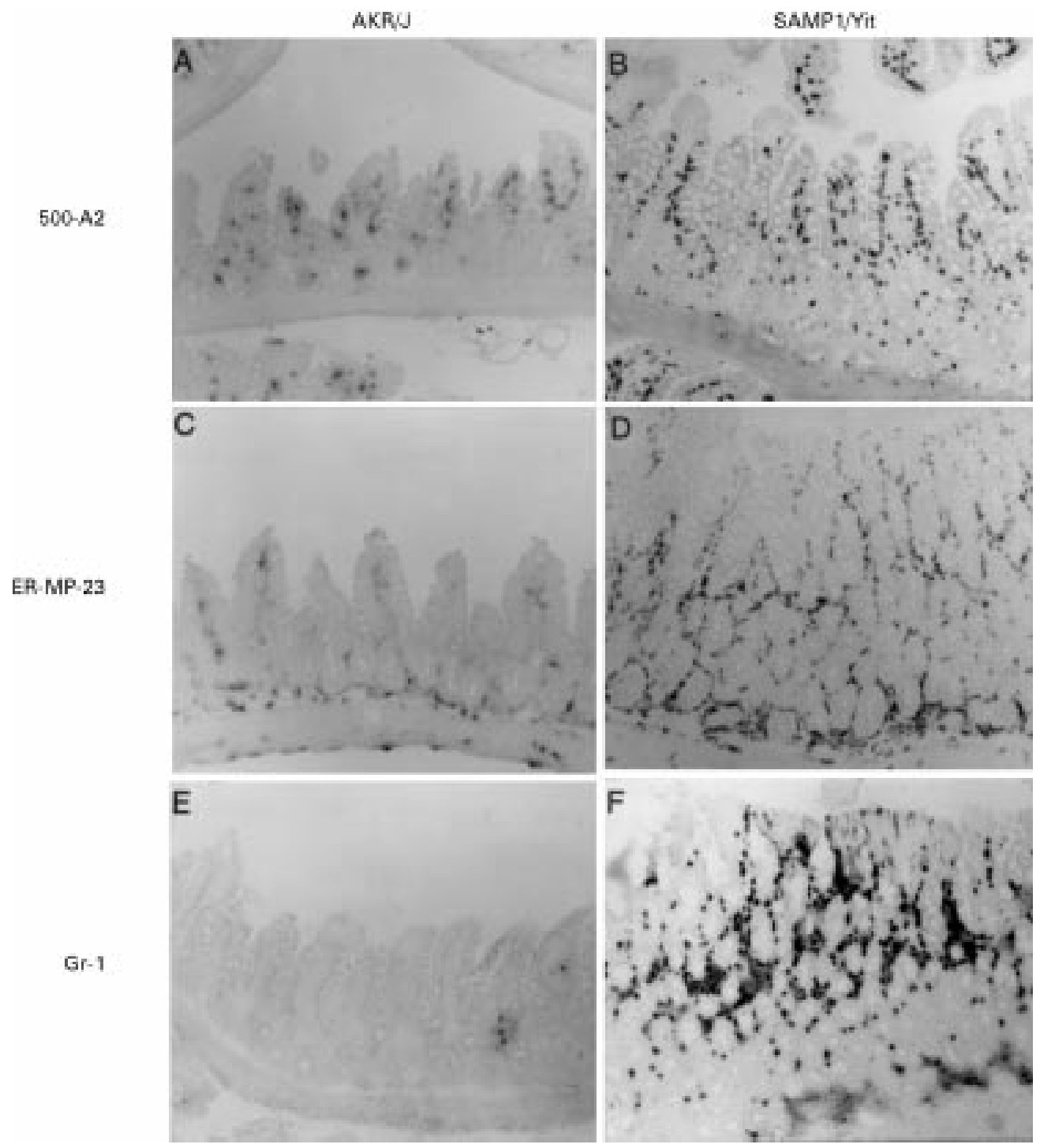

Figure 3 Immunohistochemical staining of the ileal mucosa. A cryostat section from IBD SAMP1/Yit and age matched control AKR/f mice was stained with monoclonal antibodies 500-A2, ER-MP-23, and Gr-1 that recognise CD3-E, tissue

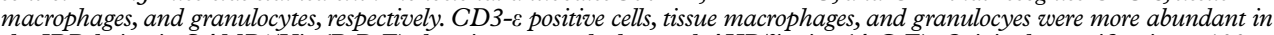
the IBD lesion in SAMP1/Yit $(B, D, F)$ than in age matched control $A K R / \mathcal{F}$ mice $(A, C, E)$. Original magnification, $\times 100$.

and age matched $\mathrm{AKR} / \mathrm{J} \quad(\mathrm{n}=3)$ mice was homogenised with a polytoron homogeniser in hexadecyltrimethylammonium bromide (Sigma Chemical Co., St Louis, Missouri, USA) buffer. The suspension was sonicated on ice and centrifuged at $15000 \mathrm{rpm}$ for 30 minutes. The supernatant was mixed with enzyme substrate buffer containing O-dianisidine hydrochloride (Sigma) $0.167 \mathrm{mg} / \mathrm{ml}$ and $0.0005 \%$ hydrogen peroxide. The changes in the absorbance at $455 \mathrm{~nm}$ were measured.

EFFECTS OF ENTERIC BACTERIA ON THE DEVELOPMENT OF IBD IN THE SAMP1/Yit STRAIN To determine the effect of enteric bacteria on the development of gut inflammation in the SAMP1/Yit strain, GF SAMP1/Yit strain mice were conventionalised as described previously. ${ }^{18}$ In brief, after removal of GF SAMP1 (at five weeks of age) from the vinyl isolator, a faecal suspension from SPF SAMP1/ Yit mice was orally administered through a gastric tube into GF SAMP1/Yit strain mice.
Fifteen weeks after conventionalisation, the mice were sacrificed and examined for the presence of intestinal inflammation.

\section{STATISTICS}

The results of each experiment were analysed by the two tailed Student's $t$ test.

\section{Results}

CHRONIC INTESTINAL INFLAMMATORY DISEASE We observed 50 littermates of 20 week old SPF SAMP1/Yit mice and detected thickening of the intestinal wall of the terminal ileum. The discontinuous lesion was maximal in the terminal ileum and gradually decreased as it reached the upper part of the small intestine (data not shown). Histological examination revealed that the intestinal inflammation was restricted to the distal part of the small intestine (distal part of the jejunum and ileum) and caecum (fig 1). The proximal parts of the small intestine (duodenum and proximal part of the jejunum), colon, and rectum had 

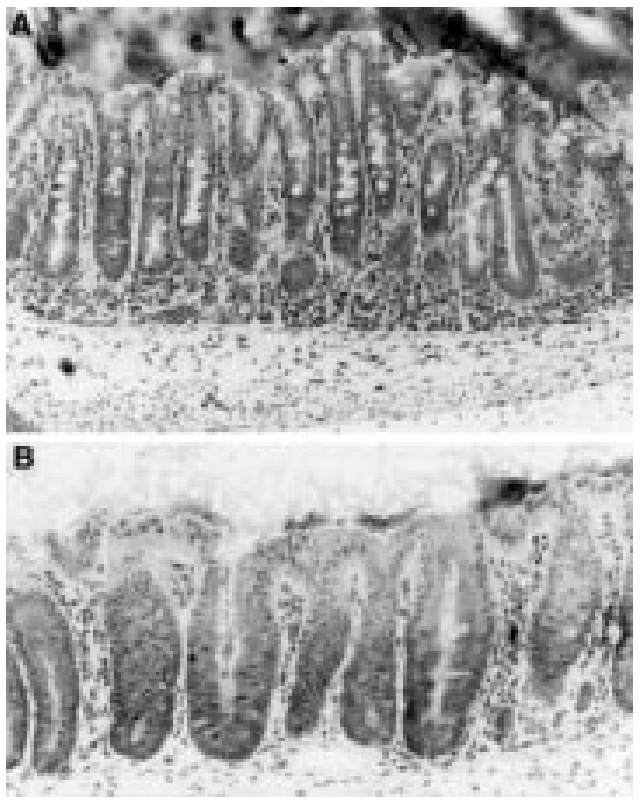

Figure 4 Histological analysis of the caecum of the $S A M P 1 / Y i t$ strain at 20 weeks of age. (A) Mild epithelial hyperplasia resulting in crypt elongation and increased mononuclear cell infiltrate in the LP. (B) Higher magnification of the caecal epithelial lesion in the $S A M P 1 / Y i t$ strain at age 20 weeks. Epithelial hyperplasia with increased mitotic figures could be seen. Note that there is goblet cell depletion. Toluidine blue stain. Original magnification: $A, \times 200 ; B, \times 400$.

histologically normal features (fig 1; data for rectum not shown). Histologically, the lesions in the ileum were characterised by thickening of the intestinal wall due to inflammation and epithelial cell hyperplasia (fig $2 \mathrm{~A}$ ). Inflammatory cells had infiltrated the lamina propria
(LP) and submucosa (fig 2B). In the lesions in the ileum, villous atrophy and crypt hyperplasia characterised by crypt elongation and increased mitotic figures were usually seen (fig $2 \mathrm{~B}, \mathrm{C}$ ). In the LP, enlargement of the lymphatic vessels was detected (fig 2B). Inflammatory infiltrates in the LP consisted of macrophages, neutrophils, and lymphocytes (fig 2D) and intraluminal neutrophils could be seen in the necrotic crypts (fig 2D). Crypt microabscesses in the ileum could be seen after 30 weeks (fig 2E).

An immunohistochemical study showed that many of the cells infiltrating the lesions were immunoreactive with monoclonal antibodies 500-A2, ER-MP23, and Gr-1 that recognise CD3- $\varepsilon$, tissue macrophages, and granulocytes respectively (fig $3 \mathrm{~B}, \mathrm{D}, \mathrm{F}$ ). The numbers of these inflammatory cells were quite low in age matched control AKR/J mice or non-inflamed intestinal mucosa of SAMP1/Yit mice (fig $3 \mathrm{~A}, \mathrm{C}, \mathrm{E})$. The lesions in the caecum were characterised by hyperplasia of the crypt epithelial cells and cellular infiltration in the LP (fig 4). However, the intestinal inflammation in the caecum was less severe than that in the ileum. By immunohistochemical analysis, the inflammatory infiltrates in the caecum consisted of macrophages, lymphocytes, and a few neutrophils (data not shown). Crypt elongation with increased mitotic activity and the loss of goblet cells was pronounced in the epithelial layer (fig 4B). Caecal inflammation was observed mainly in the region around the ileocaecal junction, and inflammation of other caecal regions was mild or not detected (data not shown).
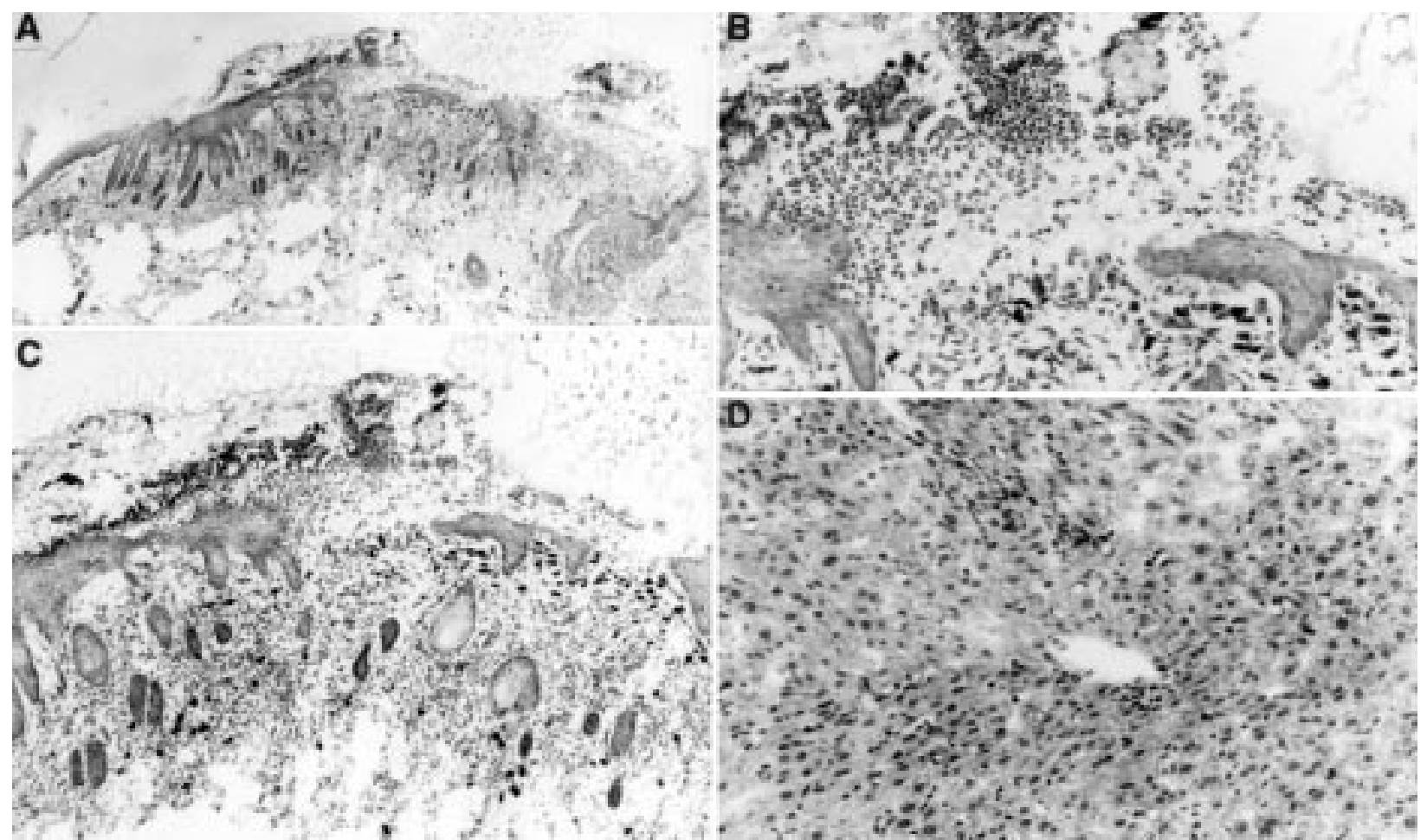

Figure 5 Histological analysis of the skin and liver. (A) Pathology of the dorsal skin in the SPF SAMP1/Yit strain at 20 weeks of age. Loss of the epidermis can be seen in the right side of the photograph. (B) High power view of A. Inflammatory infiltrates can be seen in the dermis. (C) Higher magnification of $A$. A large number of neutrophils covered the epidermal ulceration. (D) Histopathology of the liver in SPF SAMP1/Yit mice at 30 weeks of age. A focal mononuclear cell infiltrate could be detected throughout the hepatic acini. Toluidine blue stain. Original magnification: $A, \times 40 ; B, \times 100$; $C, \times 200 ; D, \times 400$. 
Table 1 Incidence of histological inflammatory lesions in SPF SAMP1/Yit mice

\begin{tabular}{ll}
\hline Tissue & Incidence \\
\hline Stomach & $0 / 45$ \\
Duodenum & $0 / 50$ \\
Jejunum & $50 / 50$ \\
Ileum & $50 / 50$ \\
Caecum & $48 / 50$ \\
Proximal colon & $0 / 50$ \\
Distal colon & $0 / 50$ \\
Rectum & $0 / 50$ \\
Salivary gland & $0 / 30$ \\
Pancreas & $0 / 47$ \\
Liver & $22 / 50$ \\
Lung & $0 / 30$ \\
Kidney & $0 / 30$ \\
Skin & $45 / 50$ \\
\end{tabular}

(2)

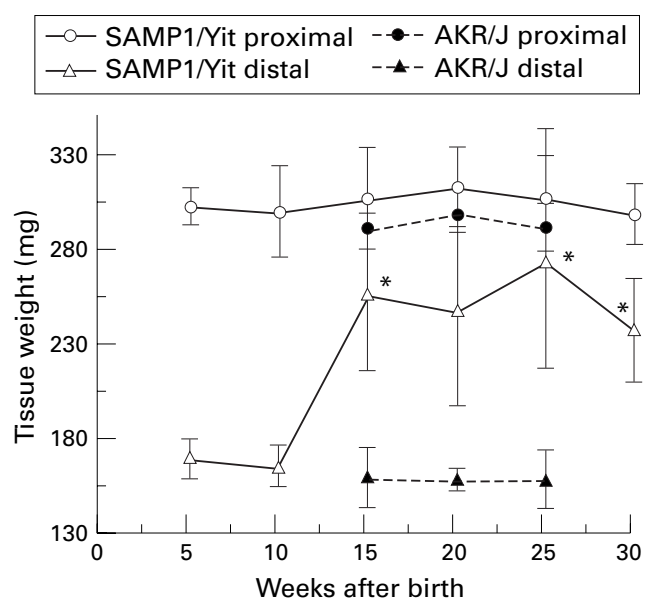

Figure 6 Ontogenic study of the inflammatory disease. Values are means $(S D) .{ }^{\star}$ Significantly different $(p<0.05)$ from the initial tissue weight.

HISTOLOGICAL ANALYSIS OF THE SKIN AND OTHER ORGANS

Intestinal inflammation was correlated with the presence of skin lesions in SPF SAMP1/Yit mice. Ninety per cent $(45 / 50)$ of the SPF SAMP1/Yit mice had skin lesions in the dorsal part of the skin and eyelid (table 1). The lesion in the skin showed loss of the epidermis and infiltration of inflammatory cells into the dermis (fig 5A,B). A large number of neutrophils covered the lesion (fig 5C). Histologi- cal analysis of the other organs such as lung, salivary gland, kidney, stomach, and pancreas were normal (table 1). However, cellular infiltration could be detected in the liver in SAMP1/Yit mice. Focal clusters of lymphocytes were scattered throughout the hepatic acini (fig 5D).

ONTOGENIC STUDY OF INFLAMMATORY DISEASE

Next we examined the effect of aging on the development of the intestinal lesions. The tissue weight of the proximal part of the small intestine remained unchanged from age 5 to 30 weeks (fig 6). However, the weight of the distal part of the small intestine increased at age 15 weeks. The tissue weight of the distal part of the small intestine did not change from age 15 to 25 weeks in the SAMP1/Yit strain (fig 6). The weight of the intestine in control AKR/J mice did not change from 15 to 30 weeks. Histological analysis revealed that the intestinal lesions did not develop until age 10 weeks (data not shown).

EXPRESSION OF INFLAMMATORY MEDIATORS

The expression of iNOS was observed in the ileal epithelial cells in both SAMP1/Yit and age matched AKR/J mice. However, iNOS positive LP cells were more numerous in 20 week old SAMP1/Yit mice than in age matched AKR/J mice (fig 7A). In RT-PCR analysis, the mRNA of iNOS in the ileum increased as the disease
A

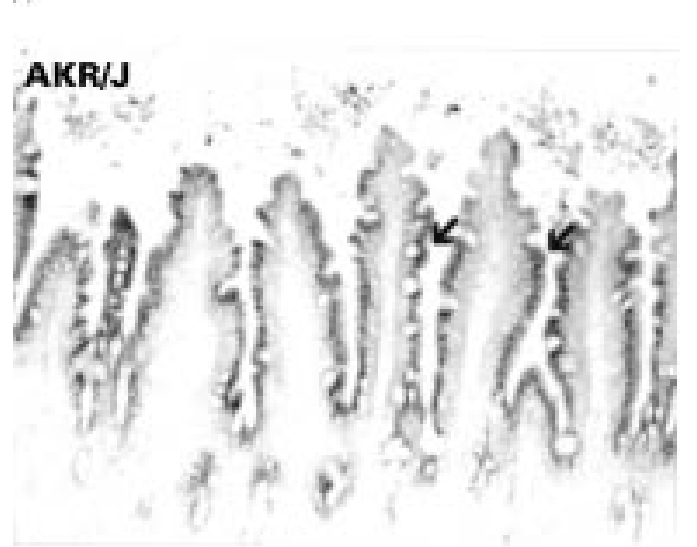

SAMP1/Yit

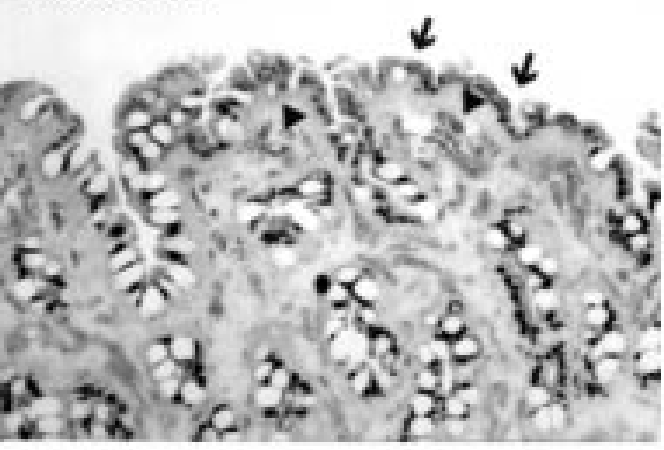

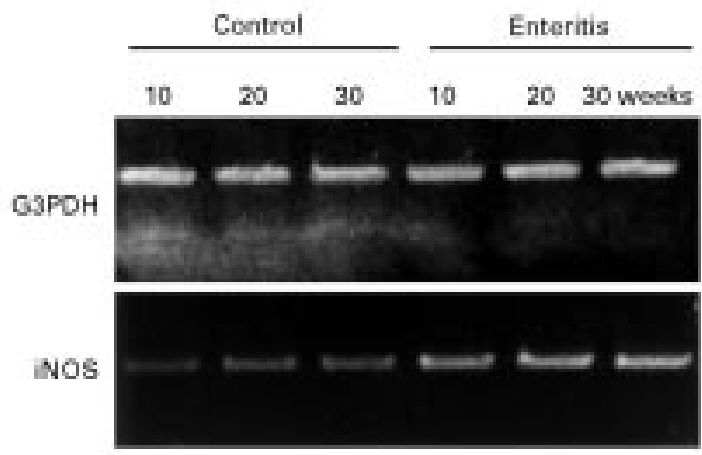

C

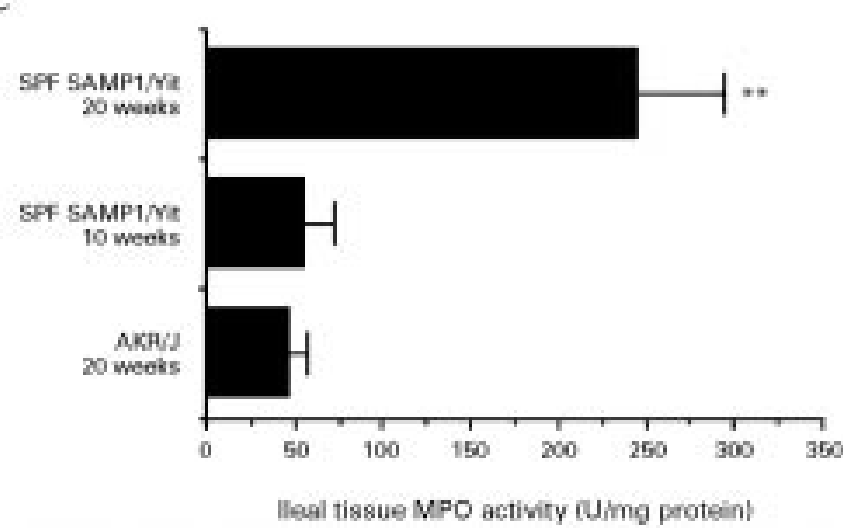

Figure 7 Expression of inflammatory mediators. (A) Immunostaining of iNOS in the SAMP1/Yit strain. The expression of $i N O S$ on the epithelial cells could be seen in both SPF SAMP1/Yit and control AKR/F mice at 20 weeks of age (arrow). However, there were more iNOS expressing cells in the LP in the 20 week old SAMP1/Yit strain than in the age matched AKR/f strain (arrowhead). Original magnification $\times 100$. (B) RT-PCR analysis of $i N O S$ $m R N A$. The $m R N A$ of iNOS increased in the ileum during disease development. (C) Analysis of tissue MPO activity. Tissue MPO activity in ileum was higher in the 20 week old SAMP1/Yit strain than in the age matched AKR/f strain. There were three mice per group. Similar results were obtained from two independent experiments. Values are means $(S D) .{ }^{\star \star}$ Values significantly different $(p<0.01)$ from control. 
A
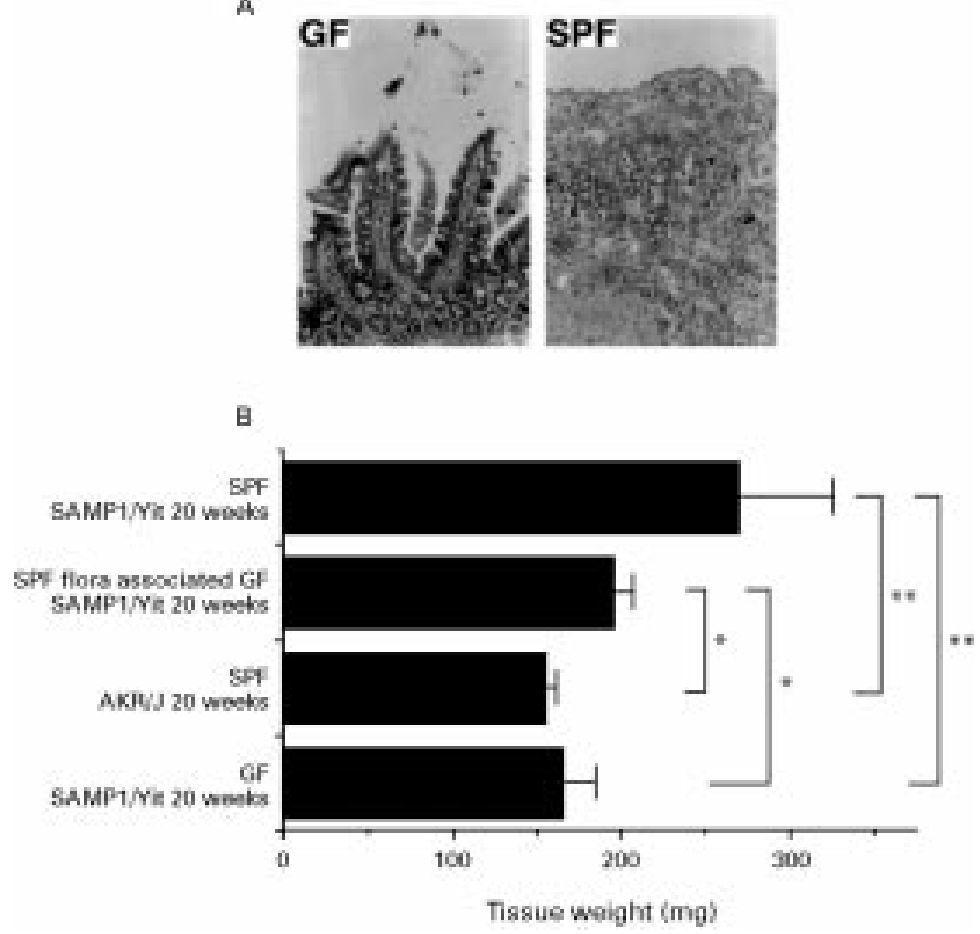

Figure 8 Effect of intestinal microflora on development of the disease. (A) In the GF $S A M P 1 / Y i t$ strain, the intestinal inflammatory disease that was seen under SPF conditions could not be detected, at least until 30 weeks of age. The intestinal architecture in GF littermates was quite normal, as in other strains of $G F$ mice. (B) After contamination of 5 week old GF SAMP1/Yit mice with a faecal suspension from SPF AKR/F mice, the weight of the distal part of the small intestine was increased compared with that of age matched GF SAMP1/Yit mice $(n=5)$ after 15 weeks. There was no difference in the intestinal tissue weight between GF SAMP1 and SPF AKR/F mice $(p=0.4953)$. Values are means $(S D)$. Values significantly different $\left({ }^{\star} p<0.05 ;{ }^{\star *} p<0.01\right)$ from tissue weight of the $G F$ SAMP1/Yit strain. proximal or distal colon) does not show the inflammatory disease by the age of 30 weeks. Data obtained in this study showed that all SPF SAMP1/Yit mice developed chronic intestinal inflammation until 10 weeks of age. This subline did not have the short life span or spontaneous amyloidosis that was seen in the original SAMP1 strain. ${ }^{11-13}$ The intestinal disease consisted of a discontinuous lesion, beginning in the terminal ileum. The severity of the intestinal inflammation in the caecum was less than that in the ileum. The ileal lesion contained a large number of $\mathrm{CD}^{+} \mathrm{T}$ cells, macrophages, and neutrophils. Mucosal MPO activity and $\mathrm{NO}$ expression in the ileum were increased in this strain of mice. These pathophysiological characteristics shown in SAMP1/ Yit mice have some similarities to other murine IBD models. ${ }^{19} 20$

The mechanism underlying the chronic intestinal inflammation in the SAMP1/Yit strain is unclear. The original SAMP1 strain showed age related immune dysfunction, especially in the $\mathrm{T}$ cell dependent antibody response. ${ }^{14}$ Hosokawa et al showed that this deficient antibody response was due to a decrease in the T helper cell function. ${ }^{15}$ Recent reports indicated that injection of the Th1-like CD45RB ${ }^{\text {high }}$ CD4 subset into scid mice induced colitis, which was prevented by coinjection of the Th2-like CD45RB ${ }^{\text {low }}$ CD4 subset or IL-10 treatment. $^{21}{ }^{22}$ Injection of the self reactive Th1 CD4 subset led to the development of diabetes in NOD mice, and was prevented by coinjection of the Th2 CD4 subset. ${ }^{23}$ We have found that transfer of the sorted CD4 subset from the SAMP1/Yit strain to scid mice induced intestinal inflammatory disease (manuscript in preparation). These studies suggest that an immune imbalance in the target organ may be the major cause of development of the organ specific inflammatory disease.

With respect to the pathogenesis of IBD, we hypothesise that the disease is due to an abnormal response to gut luminal contents. Our previous studies have shown that the gut microflora is closely related to the establishment of the host mucosal immune systems. ${ }^{17}{ }^{24-26}$ In this study, we observed that the GF SAMP1/Yit strain did not develop the intestinal inflammatory disease, and that conventionalisation of the GF SAMP1/Yit strain induced gut inflammation. Sadlack et al showed that disruption of the IL-2 gene led to the development of colitis under SPF conditions but not in the GF state. ${ }^{1}$ We could not detect any murine pathogens such as $H$ hepaticus in our animal colonies which induce intestinal inflammation in immune deficient strains. ${ }^{27}$ These results suggest that the IBD-like enteritis and caecitis observed in these mice result from a response to the normal non-pathogenic microflora. The identity of the indigenous bacteria which cause the intestinal inflammation in our model system is being investigated. We observed that the gut inflammation in the conventionalised SAMP1/Yit mice was less severe than that in age matched SPF SAMP1/Yit mice. The mechanism underlying this phenomenon is

\section{Discussion}

The SAMP1/Yit strain, a new SAMP1 subline, develops IBD in the terminal ileum and caecum. However, the large intestine (the 
unknown. It is possible that the time of bacterial colonisation may be important for the progression of disease in this model.

The enteritis and caecitis in the SAMP1/Yit strain described here may become a model system of human IBD. This strain should be useful for investigating the incidence and progression of IBD from the viewpoint of the interaction between intestinal microflora and the host immune system.

The authors wish to thank Drs H Amasaki (Nippon Veterinary and Animal Science University), and T Osawa, T Watanabe, and $\mathrm{T}$ Takahashi (Yakult Central Institute) for their advice regarding the manuscript.

1 Sadlack B, Merz H, Schorle H, et al. Ulcerative colitis-like disease in mice with a disrupted interleukin-2 gene. Cell 1993;75:253-61.

2 Kuhn R, Lohler J, Rennick D, et al. Interleukin-10-deficient mice develop chronic enterocolitis. Cell 1993;75:263-74.

3 Mombaerts P, Mizoguchi E, Grusby MJ, et al. Spontaneous development of inflammatory bowel disease in $\mathrm{T}$ cell receptor mutant mice. Cell 1993;75:275-82.

4 Powrie F, Leach MW, Mauze S, et al. Phenotypically distinct Powrie F, Leach MW, Mauze S, et al. Phenotypically distinct subsets of $\mathrm{CD}^{+} \mathrm{T}$ cells induce or protect from chronic intestinal inflammat

5 Stange EF, Fleig WE, Rekhlaw E, et al. Cyclosporin A treatment in inflammatory bowel diseases. Dig Dis Sci 1989;34 1387-92.

6 Sundberg JP, Elson CO, Bedigian H, et al. Spontaneous, heritable colitis in a new substrain of $\mathrm{C} 3 \mathrm{H} / \mathrm{HeJ}$ mice. Gastoroenterology 1994;107:1726-35.

7 Okuyasu I, Hatakeyama S, Yamada M, et al. A novel method in the induction of reliable experimental acute and chronic ulcerative colitis in mice. Gastroenterology 1990;98:694702 .

8 Beagley KW, Cummings OW, Black CA, et al. Experimentally induced colitis in mice. In: Tuchiya M, ed. Frontiers of mucosal immunology. Vol 1. Amsterdam: Elsevier Science, 1991:847-50.

9 Brakic T, Banic M, Grabarevic Z, et al. A model of inflammatory bowel disease induced by 2,4-dinitrofluorobenzene in previously sensitized BALB-c mice. Scand $\mathcal{f}$ Gastroenterol in previously sensit

10 Takeda T, Hosokawa M, Takeshita S, et al. A new murine model of accelerated senescence. Mech Ageing Dev

11 Takeda $\mathrm{T}$. The $S A M$ model of senescence. International Congress Series 1062. Amsterdam: Elsevier Science, 1994 $15-22$

12 Higuchi K, Matsumura A, Hashimoto K, et al. Isolation and characterization of senile amyloid-related antigenic substance $\left(\mathrm{SAS}_{\mathrm{SAM}}\right)$ from mouse serum. F Exp Med 1983;158: $1600-14$
13 Matsushita M, Tsuboyama T, Kasai R, et al. Age-related changes in bone mass in the senescence-accelerated mouse (SAM). Am f Pathol 1986;125:276-83.

14 Hosokawa $\mathrm{T}$, Hosono $\mathrm{M}$, Higuchi $\mathrm{K}$, et al. Immune responses in newly developed short-lived SAM mice. I. Age-associated early decline in immune activities of cultured spleen cell. Immunology 1987;62:419-23.

15 Hosokawa $T$, Hosono $M$, Haneda $K$, et al. Immune responses in newly developed short-lived SAM mice. II. Selectively impaired T-helper cell activity in in vitro antibody response. Immunology 1987;62:425-9.

16 Japan Experimental Animal Research Association. Recommended requirement for sterility test of germfree animals, provisional. Experimental Animals 1972;21:35-8.

17 Krawisz JE, Sharon P, Stenson F. Quantitative assay for acute intestinal inflammation based on myeloperoxidase activity. Gastroenterology 1984;87:1344-50

18 Matsumoto M, Setoyama H, Umesaki Y. Differential induction of major histocompatibility complex molecules on mouse intestine by bacterial colonization. Gastroenterology 1992;103:1777-82.

19 Berg DJ, Davidson, Kuhn R, et al. Enterocolitis and colon cancer in interleukin-10-deficient mice are associated with aberrant cytokine production and CD4+ TH1-like responses. F Clin Invest 1996;98:1010-20.

20 Aiko S, Grisham MB. Spontaneous intestinal inflammation and nitric oxide metabolism in HLA-B27 transgenic rats. Gastroenterology 1995;109:142-50.

21 Powrie F, Correa-Oliveira R, Mauze S, et al. Regulatory interactions between CD45RB ${ }^{\text {high }}$ and CD45RB ${ }^{\text {low }} \mathrm{CD} 4^{+} \mathrm{T}$ cells are important for the balance between protective and pathogenic for the cell-mediated immunity. F Exp Med 1994;179:589-600.

22 Powrie F, Leach MW, Mauze S, et al. Inhibition of Th1 responses prevents inflammatory bowel disease in scid mice reconstituted with $\mathrm{CD} 45 \mathrm{RB}^{\text {high }} \mathrm{CD} 4^{+} \mathrm{T}$ cells. Immunity 1994;1:553-62.

23 Katz JD, Benoist C, Mathis D. T helper cell subsets in insulin-dependent diabetes. Science 1995;268:1185-8.

24 Umesaki Y, Setoyama H, Matsumoto S, et al. Expansion of $\alpha \beta$ T-cell receptor-bearing intraepithelial lymphocytes after microbial colonization in germ-free mice and its independence from thymus. Immunology 1993;79:32-7.

25 Okada Y, Setoyama H, Matsumoto S, et al. Effects of fecal microorganisms and their chloroform-resistant variants derived from mice, rats, and humans on immunological and physiological characterictics of the intestine of ex-germfree mice. Infect Immun 1994;62:5442-6.

26 Umesaki Y, Okada Y, Matsumoto S, et al. Segmented filamentous bacteria are indigenous intestinal bacteria that activate intraepithelial lymphocytes and induce MHC class II molecules and fucosyl asialo GM1 glycolipids on the small intestinal epithelial cells in the ex-germ-free mouse. Microbiol Immunol 1995;39:555-62.

27 Cahill RJ, Foltz CJ, Fox JG, et al. Inflammatory bowel disease: an immunity-mediated condition triggered by bacterial infection with Helicobacter hepaticus. Infect Immun 1997;65:3126-31. 